\title{
Implementation of Dose Monitoring Software in the Clinical Routine: First Experiences
}

\section{Einführung einer Dosis-Monitoring-Software in den klinischen Alltag: Erste Erfahrungen}

Authors

Affiliations
C. Heilmaier $^{1}$, N. Zuber ${ }^{1}$, B. Bruijns ${ }^{1}$, C. Ceyrolle ${ }^{2}$, D. Weishaupt ${ }^{1}$

Department of Radiology and Nuclear Medicine, Stadtspital Triemli, Zurich, Switzerland

DoseWatch, GE Healthcare, Buc, France
Key words

- CT

- radiation safety

- QA/QC received 19.5.2015

accepted 17.7.2015

Bibliography

DOI http://dx.doi.org/

10.1055/s-0041-106071

Published online: 30.9.2015

Fortschr Röntgenstr 2016; 188:

82-88 @ Georg Thieme Verlag

KG Stuttgart · New York .

ISSN 1438-9029

\section{Correspondence}

\section{Miss Christina Heilmaier}

Department of Radiology and Nuclear Medicine, Stadtspital Triemli

Birmensdorferstrasse 497

8063 Zurich

Switzerland

Tel.: ++ 41/44/4661452

Fax: ++41/44/4663426

christina.heilmaier@triemli.

zuerich.ch

\section{Zusammenfassung}

$\nabla$

Ziel: Die Strahlenbelastung der Bevölkerung durch medizinische Bildgebung hat in den letzten Jahrzehnten deutlich zugenommen. Um die Strahlenbelastung der Patienten systematisch aufzeichnen und kontrollieren zu können, wurde in unserem Institut eine Dosis-Monitoring-Software installiert und zunächst mit den Computertomografen (CTs) verbunden.

Material und Methoden: Mithilfe der Dosis-Monitoring-Software wurden die Dosisdaten von zwei CTs zwischen Juli 2014 und Februar 2015 retrospektiv ausgewertet. Das eine CT befindet sich neben der Notaufnahme („Notfall-CT“), das andere CT wird überwiegend für stationäre und ambulante Patienten verwendet („Routine-CT“). Die Daten wurden im Hinblick auf die Anzahl der Untersuchungen mit Dosiswerten oberhalb festgelegter Schwellenwerte („Alerts“) ausgewertet und die Ursachen für diese für beide CTs analysiert. Um signifikante Unterschiede zwischen beiden Geräten festzustellen, wurden Chi-Quadrat-Tests durchgeführt.

Ergebnisse: Insgesamt wurden 8883 Untersuchungen akquiriert (Routine-CT: 3415, NotfallCT: 5468). Hierbei wurden 316 Alerts registriert (Quote: 4\%). Die Quote der Alerts schwankte zwischen 2 und $5 \%$ zwischen den Monaten und Geräten, wobei am Routine-CT signifikant mehr Alerts nachgewiesen wurden. Ursachen für die Alerts waren hoher BMI (51\%), ungenaue Lagerung der Patienten im Isozenter (24\%), Untersuchungswiederholungen (11\%), Artefakte durch einliegendes Osteosynthesematerial (9\%) oder andere Gründe $(5 \%)$. Scanwiederholungen waren signifikant häufiger am Notfall-CT notwendig $(p=0,019)$, während hoher BMI, ungenaue Patientenlagerung oder einliegendes Osteosynthesematerial öfter Alerts am Routine-CT verursachten (für alle $p<0,05$ ). Es zeigte sich eine gute Korrelation zwi-

\section{Abstract \\ $\nabla$}

Purpose: Radiation exposure of the public as a result of medical imaging has significantly increased during the last decades. To have a tool to register and control patient dose exposure, we implemented dose monitoring software at our institution and first connected our computed tomography (CT) scanners.

Materials and Methods: CT dose data from July 2014 to February 2015 was retrospectively analyzed using dose monitoring software. We evaluated a number of scans above predefined dose thresholds ("alerts"), assessed reasons for alerts and compared data of two CT scanners, one located close to the emergency room ("emergency CT scanner") and one mainly used on an outpatient basis ("clinical routine CT scanner"). To check for statistically significant differences between scanners, chi-square-tests were performed.

Results: A total of 8883 scans were acquired (clinical routine CT scanner, $n=3415$; emergency CT scanner, $\mathrm{n}=5468$ ) during which 316 alerts were encountered (alert quota, $4 \%$ ). The overall alert quota ranged from $2-5 \%$ with significantly higher values for the clinical routine CT scanner. Reasons for alerts were high BMI (51\%), patient offcentering $(24 \%)$, scan repetition (11\%), orthopedic hardware $(9 \%)$, or other $(5 \%)$. Scan repetition was necessary significantly more often with the emergency CT scanner $(p=0.019)$, while high $\mathrm{BMI}$, off-centering and orthopedic hardware were more frequently seen with the clinical routine $\mathrm{CT}$ scanner (for all, $\mathrm{p}<0.05$ ). There was a good correlation between high body weight and dose above threshold $(r=0.585)$.

Conclusion: Implementation of dose monitoring software in the clinical routine was successfully accomplished and provides important information regarding patient radiation protection. 
schen dem BMI und den Dosiswerten über dem Schwellenwert $(\mathrm{r}=0,585)$.

Schlussfolgerung: Eine Dosis-Monitoring-Software kann erfolgreich in den klinischen Alltag eingeführt werden und liefert wichtige Informationen betreffend den Strahlenschutz der Patienten.

Kernaussagen:

1. Eine Dosis-Monitoring-Software kann erfolgreich in den klinischen Alltag eingeführt werden.

2. Dosiswarnungen sind entweder durch menschliche Fehler oder patientenspezifische Faktoren bedingt.

3. Durch eine Dosis-Monitoring-Software werden wichtige Informationen betreffend den Strahlenschutz der Patienten gewonnen.
Key Points:

1. Implementation of dose monitoring software in the clinical routine can be successfully accomplished.

2. Dose notifications are due to human error or patient-specific factors.

3. Dose monitoring software provides important information regarding radiation protection of patients.

Citation Format:

- Heilmaier C, Zuber N, Bruijns B etal. Implementation of Dose Monitoring Software in the Clinical Routine: First Experiences. Fortschr Röntgenstr 2016; 188: 82-88

\section{Introduction}

Radiation exposure of the public due to medical imaging has dramatically increased during the last decades, which is stressed by the fact that the number of computed tomography scans performed increased by $1900 \%$ in the United States from 1980 to 2005 [1,2]. Despite the introduction of multiple new technologies such as dose modulation, low-dose protocols, and reconstruction algorithms, annual radiation exposure due to medical imaging currently makes up almost $50 \%$ of the yearly background radiation exposure per capita [2]. As a consequence, reasonable dose management has become more and more important and has gained public visibility [3]. To account for this, the American College of Radiology (ACR) has introduced the Dose Index Registry (DIR) as part of the National Radiology Data Registry [4] and has initiated campaigns to increase awareness of radiation protection ("Image Wisely" for adults [5]; "Image Gently" for pediatrics [6, 7]) with similar projects existing in Europe ("EuroSafe" [8]).

With regard to computed tomography (CT), important radiation dose quantities are the volumetric CT dose index $\left(\mathrm{CTDI}_{\mathrm{vol}}\right)$ and the dose length product (DLP), which are routinely displayed on every CT console. They are measured using cylindrical phantoms $[4,9]$. In most countries the DLP is the quantity used for setting national dose reference levels (DRLs).

To account for an increasing demand of dose control, several dose monitoring programs have been launched. This software allows for in-house quality assurance by analysis of dose levels, by identification of dose outliers as well as by reviewing the radiation exposure of different scanners. Moreover, this software enables comparison of one's own dose data with national DRLs $[4,10]$ and aggregation of data for a national dose registry based on exam type and body part [4]. However, so far little is known about the feasibility of introducing dose monitoring software in the clinical routine. Therefore, the aim of the present study was to report on first experiences gained in a large public hospital after connection of dose monitoring software to two computed tomography scanners and the software's implementation in the daily clinical routine. Furthermore, analysis of excess dose notifications was performed to assess the most frequent sources of radiation exposure above predefined thresholds.

\section{Methods}

$\nabla$

Our local ethics committee approved analysis of the dose monitoring software's data as part of the hospital's quality assurance. Informed consent was waived.

\section{Dose monitoring software}

GE's (GE Healthcare Systems, Buc, France) dose management solution DoseWatch ${ }^{\circledR}$ was implemented at our institution to improve radiation protection, while maintaining high diagnostic quality of images. DoseWatch ${ }^{\circledR}$ is web-based software that allows for capturing, tracking, and reporting radiation dose information directly from any imaging device and was first connected to our computed tomography (CT) scanners. The software offers detailed analysis on the dose delivered to the patients and can be adapted to one's own preferences. Dose data analysis is possible for all scanners together as well as separately for each scanner, thereby allowing for comparison of dose data between different scanners. Moreover, the software inherits a notification system that transmits messages when dose levels exceed predefined thresholds ("alerts"). At the time as the installation of the software, national dose reference levels (DRLs) for 21 indication-based CT examinations, which were set as dose thresholds, were available in our country. For all other protocols we decided to derive DRLs by determining the $75^{\text {th }}$ percentile of the distribution of a defined dosimetric quantity [11]. The software received dose information as a separate file based on the dose protocol of the scanners, which included scout images for the assessment of patient diameter and positioning.

\section{Study setup}

The dose monitoring software was installed on a virtual server. - Fig. 1 illustrates the standard dose monitoring workflow as currently practiced in our institution. A dose team consisting of two radiographers, one board certified radiologist, and the institution's IT specialist supervises the workflow. They meet once a month to discuss dose data and coordinate tasks associated with the dose monitoring software.

In our institution each CT examination is justified by either a board certified radiologist or a radiology resident. Justification encompasses choosing the adequate CT protocol in order to address the clinical question. As no national standards exist, CT protocols are specific for our institution and are not mapped to the RadLex [4]. Given that our CT scanners are from the same vendor, protocol names are identical for all scanners. 


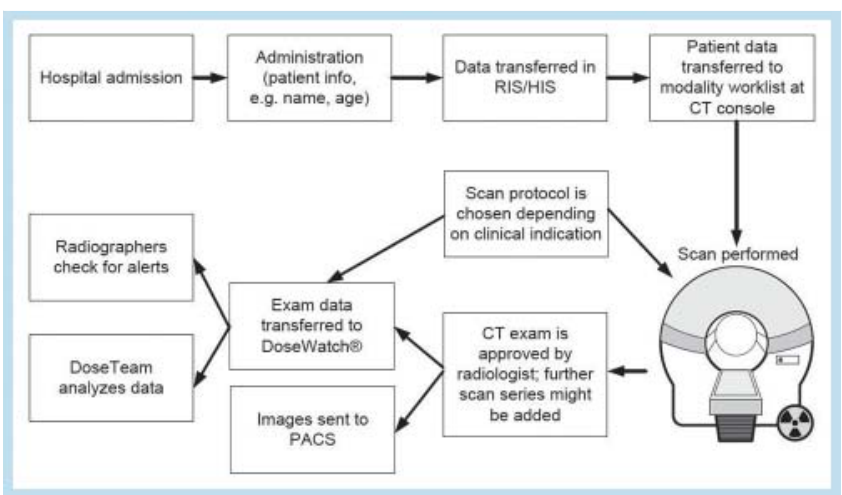

Fig. 1 Scheme of the standard dose monitoring workflow as practiced in our institution. HIS= Hospital Information System. RIS= Radiology Information System

Abb. 1 Zusammenstellung der Standardabläufe betreffend der Dosisüberwachung an unserem Institut. HIS = Krankenhausinformationssystem. RIS = Radiologie-Informationssystem .

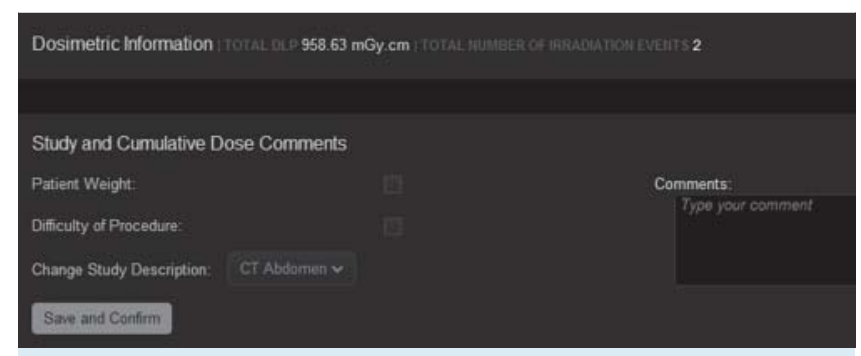

Fig. 2 Illustration of the alert answering window. Radiographers can either click on one of the predefined comments as seen on the left (e. g. patient weight) or can type their comment in the box on the right site.

Abb.2 In dem dargestellten Fenster können die Röntgenassistenten die Dosiswarnungen beantworten, indem sie entweder einen vorgegebenen Kommentar (z. B. Patientengewicht) auswählen oder eine Bemerkung in das entsprechende Feld auf der rechten Seite schreiben.

Our workflow includes approval of every CT scan by a board certified radiologist or a radiology resident before the patient is allowed to leave the CT bed. For that reason it is possible for further scan series to be added (e.g. a delayed phase), although they were not part of the initially planned CT protocol. Because contextual integration between our Radiology Information System (RIS) and the dose monitoring software is not established yet, the software cannot register any change of protocol made after the scan has already started. To avoid dose data being linked to the wrong CT protocol, radiographers were advised to make a note in the comment box of the software, whenever the protocol differed from the initially chosen protocol. The correct study name was then manually selected within the dose monitoring software, before data analysis began.

As part of our dose monitoring policy, the dose monitoring software continuously runs on a separate computer next to the CT scanning console and radiographers are advised to check for alerts after each scan. In case of a dose notification, radiographers are trained to answer them by either clicking on predefined answers (e.g. patient weight) or giving short explanations (e.g. repetition of scan due to severe movement artifacts) within the software's comment box ( $\bullet$ Fig. 2).
The radiographers involved in the present study had an average working experience of 8.32 years after certification (range: 1 41 years).

\section{CT scans}

CT data sets were acquired on our two multidetector-row CT scanners. One of these two CT scanners is mainly used on an outpatient basis (Discovery HD 750, GE Healthcare Systems, Milwaukee, WI, USA) and therefore is called clinical routine CT. The second CT scanner is installed close to the emergency room ("emergency CT"; LightSpeed VCT, GE Healthcare Systems, Milwaukee, WI, USA) and is primarily used for the imaging of patients from the emergency room or the intensive care units as well as for CT-guided percutaneous interventions. Both CT scanners are equipped with the latest reconstruction algorithms such as the iterative reconstruction algorithm.

Depending on clinical indication, protocols were chosen and scans were performed native or after contrast media application (intravenous, oral and/or rectal), adhering to the as low as reasonably achievable (ALARA) principle. The applied study protocols, their scan parameters as well as the set dose thresholds are summarized in $\bullet$ Table 1.

\section{Statistical analysis \\ $\nabla$}

Data analysis was done by a board certified radiologist with 10 years of experience in $\mathrm{CT}$ and with a special interest in radiation protection. For the purpose of this study, data from July 2014 until February 2015 was retrospectively evaluated with a focus on the volumetric CT dose index ( $\mathrm{CTDI}_{\text {vol }}$; milli-Gray (mGy)) and the dose length product (DLP; $\mathrm{MGy}^{*} \mathrm{~cm}$ ). Moreover, study description, patient gender and age as well as body mass index (BMI; $\mathrm{kg} / \mathrm{m}^{2}$ ) were recorded. A BMI $\geq 25 \mathrm{~kg} / \mathrm{m}^{2}$ was deemed to represent excess BMI.

The radiologist revised all alerts gained during the investigation period, analyzed reasons for notifications and compared data of the emergency and clinical routine scanner. Besides high BMI, one possible cause of alert was the patient being positioned not perfectly in the isocenter of the scanner ("patient off-centering"), which was assumed if aberrations in vertical position exceeded $2 \mathrm{~cm}$.

To check for statistically significant differences between the two scanners, chi-square-tests ( $x^{2}$-test) were done with a $p$-value $>0.05$ considered to represent statistical significance. If high BMI caused the alert, the relative DLP value above the threshold was calculated and correlated with the BMI by means of the Pearson correlation coefficient.

Data was exported from the dose monitoring software as Excel spreadsheets and further analysis was then performed using either Microsoft Excel 2010 (Redmond, WA, USA) or IBM SPSS Version 22 (Amonk, NY, USA).

\section{Results}

$\nabla$

A total of 8883 CT scans were acquired during July 1, 2014 and February 28, 2015 (5468 on emergency CT scanner; 3415 on clinical routine CT scanner) and dose data of all examinations was successfully transferred to the dose monitoring software. CT scans were performed on 7914 different patients, of whom 695 underwent 2 examinations, 96 got 3 scans, 20 had 4 CTs, 
Table 1 Summary of protocol names with scan parameters and dose thresholds (dose-length product; $\mathrm{mGy}{ }^{1} \mathrm{~cm}$ ).

Tab. 1 Zusammenfassung der Protokollnamen mit den Untersuchungsparametern sowie den Dosisschwellenwerten (Dosislängenprodukt; $\mathrm{mGy}^{1} \mathrm{~cm}$ ).

\begin{tabular}{|c|c|c|c|c|c|}
\hline CT protocol & $\begin{array}{l}\text { tube voltage } \\
(\mathrm{kV})\end{array}$ & $\begin{array}{l}\text { tube current } \\
(\mathrm{mA})\end{array}$ & pitch & noise index & $\begin{array}{l}\text { DLP threshold } \\
\left(\mathrm{mG} y^{1} \mathrm{~cm}\right)\end{array}$ \\
\hline skull/brain & 120 & $120-165$ & 0.75 & 9.0 & $1000^{1}$ \\
\hline brain (vascular) & 120 & $120-335$ & 0.531 & 25.30 & $1000^{1}$ \\
\hline skull/brain/cervical spine & 120 & $120-500$ & 0.531 & $9.00-32.00$ & 1250 \\
\hline sinus & 120 & $10-290$ & 0.531 & 27.00 & $350^{1}$ \\
\hline skull/brain/neck/chest/abdomen & 120 & $100-335$ & 0.531 & $9.00-28.20$ & 1800 \\
\hline skull/brain/chest/abdomen & 120 & $100-335$ & 0.531 & $9.00-28.20$ & 1650 \\
\hline $\begin{array}{l}\text { trauma (skull/brain/cervical spine/ } \\
\text { chest/abdomen/pelvis) }\end{array}$ & 120 & $100-335$ & 0.531 & $9.00-32.00$ & 2300 \\
\hline cervical spine & 120 & $120-500$ & 0.969 & 32.00 & $600^{1}$ \\
\hline neck & 120 & $170-500$ & 1.375 & 28.20 & $600^{1}$ \\
\hline neck/chest & 120 & $120-350$ & 1.375 & 28.00 & 500 \\
\hline neck/chest/abdomen (vascular) & 120 & $120-450$ & 1.375 & 49.50 & 1300 \\
\hline chest (vascular) & 120 & $80-450$ & 1.375 & 49.50 & 375 \\
\hline chest/abdomen (vascular) & 120 & $120-450$ & 1.375 & 49.50 & 1000 \\
\hline chest/epigastrium & 120 & $80-450$ & 1.375 & 49.50 & $600^{1}$ \\
\hline heart & 100 & 500 & 0.16 & 15.03 & $1000^{1}$ \\
\hline chest & 120 & $80-135$ & 1.375 & 37.25 & $400^{1}$ \\
\hline chest/abdomen & 120 & $120-450$ & 1.375 & 28.00 & 1000 \\
\hline thoracic spine & 120 & $160-560$ & 0.984 & 25.30 & 300 \\
\hline shoulder & 120 & $120-350$ & 0.969 & 27.00 & $500^{1}$ \\
\hline elbow & 100 & $80-300$ & 0.531 & 14.00 & 200 \\
\hline wrist & 80 & $50-200$ & 0.531 & 13.50 & 100 \\
\hline lumbar spine & 120 & $160-560$ & 0.984 & 25.30 & $850^{1}$ \\
\hline abdomen/pelvis & 120 & $100-550$ & 1.375 & 35.00 & $650^{1}$ \\
\hline pelvis/lower extremity (vascular) & 120 & $100-550$ & 1.375 & 14.14 & $1000^{1}$ \\
\hline pelvis & 100 & $80-350$ & 0.984 & 35.00 & $500^{1}$ \\
\hline knee/lower leg & 120 & $80-300$ & 0.531 & 13.30 & 300 \\
\hline ankle & 100 & $80-250$ & 0.531 & 13.30 & 225 \\
\hline
\end{tabular}

${ }^{1}$ national dose reference level.

nationaler Dosisreferenzwert.

and 2 patients received 6 and 7 scans, respectively. The patient group consisted of 4511 men (57\%) and 3403 women (43\%) with a mean age of $58.6 \pm 23.9$ years, (range: 0 to 101 years). The most frequently applied CT protocols were CT of the skull/ brain (either alone or in combination with sinus and/or cervical spine; $n=2658)$, CT of the chest $(n=1546)$, CT of the chest and abdomen ( $n=2043)$, and CT of the abdomen ( $n=1918)$.

During the investigation period a total of 316 alerts were encountered: clinical routine CT scanner, $n=145$; emergency CT scanner, $n=171$. The mean alert quota was $4 \%$ with a range from $2-5 \%$ between the months. The alert quota was significantly higher on the clinical routine CT scanner in total for all months together $\left(x^{2}\right.$-value $\left.=7668, p=0.006\right)$ and in September $2014\left(x^{2}-\right.$ value $=4674, p=0.031)(\bullet$ Table 2$)$. For all other months no considerable difference was detected between the scanners (for all, $\mathrm{p}>0.05$ ).

Most alerts were seen when performing $\mathrm{CT}$ of the abdomen ( $n=136)$, CT of the skull/brain $(n=64)$, and CT of the chest-abdomen $(n=60)$. Causes of alerts were high BMI $(n=160 ; 51 \%)$, patient off-centering $(\mathrm{n}=77 ; 24 \%)$, scan repetition $(\mathrm{n}=36$; $11 \%)$, orthopedic hardware in the scanning area $(n=28 ; 9 \%)$, or other causes such as examination on a spine board $(n=15 ; 5 \%)$ (- Table 3). While most scans with alerts due to high BMI occurred in the case of CT of the abdomen ( $\mathrm{n}=117 ; 73 \%)$ or $\mathrm{CT}$ of the chest-abdomen ( $n=27 ; 17 \%)$, scan repetition was most often necessary in CT of the skull/brain $(n=29 ; 81 \%)$.
When comparing both scanners, analysis revealed that patient off-centering and orthopedic hardware significantly more frequently caused notifications on the clinical routine $\mathrm{CT}$ scanner versus the emergency CT scanner: patient off-centering, $27 \%$ vs. $22 \%, x^{2}$-value $=4831, p=0.028$; orthopedic hardware, $11 \%$ vs. $7 \%, x^{2}$-value $=4.15, p$-value $=0.042$. Although values varied noticeably between the months, overall alerts due to high BMI were significantly more often encountered on the clinical routine CT scanner: $x^{2}$-value $=6453, p=0.011$. In contrast, scan repetition led to an alert considerably more frequently on the emergency CT scanner compared to the clinical routine CT scanner: $17 \%$ vs. $5 \%, x^{2}$-value $=5514, p=0.019$. No considerable differences were detected with regard to other reasons $\left(x^{2}\right.$-val$\mathrm{ue}=0.015, \mathrm{p}=0.901$ ).

If the alert was triggered by high BMI, the threshold was exceeded by $58 \%$ on average (range, $1-171 \%$ ). There was a good correlation of the BMI and the relative dose value above the threshold $(r=0.585 ;$; Fig. 3 .

\section{Discussion}

\section{$\nabla$}

Due to the versatile use of $\mathrm{CT}[12,13]$, the number of $\mathrm{CT}$ studies has continuously increased during the last decades $[1,2,14,15]$. At the same time radiation exposure of the public from medical sources has grown by approximately $600 \%$ to reach $3.0 \mathrm{mSv}$ per capita per year $[16,17]$ and it is expected that $1-2 \%$ of all can- 


\begin{tabular}{|c|c|c|c|c|c|c|}
\hline & & & & & \multicolumn{2}{|c|}{ routine vs. emergency $\mathrm{CT}$} \\
\hline & & $\begin{array}{l}\text { no. of } \\
\text { alerts }\end{array}$ & $\begin{array}{l}\text { no. of } \\
\text { scans }\end{array}$ & $\begin{array}{l}\text { alert } \\
\text { quota }\end{array}$ & $x^{2}$-value & p-value \\
\hline \multirow[t]{3}{*}{ july 2014} & routine $\mathrm{CT}$ & 20 & 457 & $4 \%$ & \multirow[t]{3}{*}{0.106} & 0.744 \\
\hline & emergency CT & 24 & 604 & $4 \%$ & & \\
\hline & both & 44 & 1061 & $4 \%$ & & \\
\hline \multirow[t]{3}{*}{ august 2014} & routine $\mathrm{CT}$ & 13 & 431 & $3 \%$ & \multirow[t]{3}{*}{0.004} & 0.951 \\
\hline & emergency CT & 18 & 610 & $3 \%$ & & \\
\hline & both & 31 & 1041 & $3 \%$ & & \\
\hline \multirow[t]{3}{*}{ september 2014} & routine $C T$ & 24 & 417 & $6 \%$ & \multirow[t]{3}{*}{4.674} & $0.031^{1}$ \\
\hline & emergency CT & 21 & 680 & $3 \%$ & & \\
\hline & both & 45 & 1097 & $4 \%$ & & \\
\hline \multirow[t]{3}{*}{ october 2014} & routine $\mathrm{CT}$ & 25 & 487 & $5 \%$ & \multirow[t]{3}{*}{3.279} & 0.07 \\
\hline & emergency CT & 22 & 716 & $3 \%$ & & \\
\hline & both & 47 & 1203 & $4 \%$ & & \\
\hline \multirow[t]{3}{*}{ november 2014} & routine $C T$ & 18 & 416 & $4 \%$ & \multirow[t]{3}{*}{0.91} & 0.34 \\
\hline & emergency CT & 23 & 713 & $3 \%$ & & \\
\hline & both & 41 & 1129 & $4 \%$ & & \\
\hline \multirow[t]{3}{*}{ december 2014} & routine $\mathrm{CT}$ & 15 & 348 & $4 \%$ & \multirow[t]{3}{*}{2.71} & 0.1 \\
\hline & emergency CT & 17 & 695 & $2 \%$ & & \\
\hline & both & 32 & 1043 & $3 \%$ & & \\
\hline \multirow[t]{3}{*}{ january 2015} & routine $C T$ & 7 & 435 & $2 \%$ & \multirow[t]{3}{*}{1.878} & 0.171 \\
\hline & emergency CT & 22 & 766 & $3 \%$ & & \\
\hline & both & 29 & 1201 & $2 \%$ & & \\
\hline \multirow[t]{3}{*}{ february 2015} & routine $\mathrm{CT}$ & 23 & 424 & $5 \%$ & \multirow[t]{3}{*}{2.365} & 0.124 \\
\hline & emergency CT & 24 & 684 & $4 \%$ & & \\
\hline & both & 47 & 1108 & $4 \%$ & & \\
\hline \multirow[t]{3}{*}{ total } & routine $\mathrm{CT}$ & 145 & 3415 & $4 \%$ & \multirow[t]{3}{*}{7.668} & $0.006^{1}$ \\
\hline & emergency CT & 171 & 5468 & $3 \%$ & & \\
\hline & both & 316 & 8883 & $4 \%$ & & \\
\hline
\end{tabular}

Table 2 Comparison of alert quota of the clinical routine and the emergency CT scanner during July 2014 and February 2015.

Tab. 2 Vergleich der Quote der Dosiswarnungen am Routine-CT und am Notfall-CT zwischen Juli 2014 und Februar 2015.

no. $=$ number, $x^{2}$-value $=$ chi-square value

no. $=$ Anzahl, $X^{2}$-Wert $=$ Chi-Quadrat-Wert

1 indicates statistical significance $(p<0.05)$.

statistisch signfikanter Unterschied $(p<0,05)$.

cers in the United States will be attributable to CT scans in the future [18-20]. Although there is little doubt that in most cases the benefits of CT scans far outweigh the risks $[5,18]$ and that dose may not be reduced at the expense of needed diagnostic information $[13,21]$, the high number of unjustified, inappropriate and clinically unnecessary CT studies has garnered considerable media attention and has created substantial public anxiety $[3,13]$. For these reasons radiation protection is more and more in the focus of interest. To address this, some manufacturers have introduced dose monitoring computer programs, which enable tracking and reporting of ionizing radiation exposure for patients $[10,22]$ and which may potentially induce dose reduction actions [21, 23]. The present study showed on the basis of 8883 CT scans that dose monitoring software can be successfully implemented in the clinical routine and that dose data can be reliably transferred from the imaging devices to the software. Our analysis revealed that computed tomography dose values exceeded predefined thresholds on average in $4 \%$ of examinations. Reasons were high BMI (51\%), patient off-centering (24\%), scan repetition (11\%), orthopedic hardware within the scanning area ( $9 \%)$, or other causes (5\%), thus a mixture of patient-specific and user-specific reasons. Comparison of alert reasons on the clinical routine scanner and the emergency CT scanner showed that scan repetition was more frequently found on the latter. This may be explained by severe motion artifacts caused by oftentimes confused and agitated emergency patients requiring examination of the skull/brain to exclude intracerebral bleeding or stroke. In contrast, patient off- centering was more often encountered on the clinical routine CT scanner, although we assumed that time pressure would play a major role in correct patient centering. We therefore expected more patient off-centering alerts on the emergency CT scanner with its usually more hectic working environment. The importance of proper patient positioning at the isocenter and its considerable influence on both image quality and radiation dose distribution was demonstrated in several studies [24-26]. Reasons are changes in tube current-time product (e.g. by affecting the function of the automatic exposure control system), an increase of radiation dose absorbed by sensitive surface tissues, or an altered projection of organs onto the bowtie filter [24, 27]. It was shown that already relatively small aberrations in vertical position of $2-6 \mathrm{~cm}$ may result in dose increases of up to $51 \%$ [25, 26]. As patient centering is a user-specific factor and therefore controllable, we performed an in-service training for our radiographers pointing out the importance of proper patient positioning and the need to refresh their skills.

On both scanners the majority of alerts were caused by high BMI (BMI $\geq 25 \mathrm{~kg} / \mathrm{m}^{2}$ ). Based on probability distribution, we expected no significant differences in alerts due to high BMI between both scanners, but nonetheless found alerts on the clinical routine CT scanner considerably more often. One explanation might be that examinations of the abdomen are usually conducted on the clinical routine CT scanner and predominantly cause high BMI alerts due to the marked fat accumulation at the abdomen. The influence of BMI on absorbed dose and image quality is well-known 
Table 3 Sources of alerts (absolute and relative numbers) as encountered on clinical routine and emergency CT during July 2014 and February 2015.

Tab. 3 Ursachen der Dosiswarnungen (relative und absolute Werte) am Routine- und Notfall-CT zwischen Juli 2014 und Februar 2015.

\begin{tabular}{|c|c|c|c|c|c|c|c|c|c|c|c|}
\hline & & \multicolumn{2}{|l|}{ BMI } & \multicolumn{2}{|c|}{ off-centering } & \multicolumn{2}{|c|}{ repetition } & \multicolumn{2}{|c|}{ orth. hardware } & \multicolumn{2}{|c|}{ other } \\
\hline & & abs & rel & abs & rel & abs & rel & abs & rel & abs & rel \\
\hline \multirow[t]{3}{*}{ july 2014} & routine $\mathrm{CT}$ & 12 & $60 \%$ & 5 & $25 \%$ & 1 & $5 \%$ & 2 & $10 \%$ & 0 & $0 \%$ \\
\hline & emergency $\mathrm{CT}$ & 11 & $46 \%$ & 8 & $33 \%$ & 4 & $17 \%$ & 0 & $0 \%$ & 1 & $4 \%$ \\
\hline & both & 23 & $52 \%$ & 13 & $30 \%$ & 5 & $11 \%$ & 2 & $5 \%$ & 1 & $2 \%$ \\
\hline \multirow[t]{3}{*}{ august 2014} & routine $\mathrm{CT}$ & 6 & $46 \%$ & 3 & $23 \%$ & 1 & $8 \%$ & 1 & $8 \%$ & 2 & $15 \%$ \\
\hline & emergency $C T$ & 7 & $39 \%$ & 4 & $22 \%$ & 3 & $17 \%$ & 3 & $17 \%$ & 1 & $6 \%$ \\
\hline & both & 13 & $42 \%$ & 7 & $23 \%$ & 4 & $13 \%$ & 4 & $13 \%$ & 3 & $10 \%$ \\
\hline \multirow[t]{3}{*}{ september 2014} & routine $\mathrm{CT}$ & 13 & $54 \%$ & 5 & $21 \%$ & 2 & $8 \%$ & 4 & $17 \%$ & 0 & $0 \%$ \\
\hline & emergency CT & 10 & $48 \%$ & 2 & $10 \%$ & 6 & $29 \%$ & 1 & $5 \%$ & 2 & $10 \%$ \\
\hline & both & 23 & $51 \%$ & 7 & $16 \%$ & 8 & $18 \%$ & 5 & $11 \%$ & 2 & $4 \%$ \\
\hline \multirow[t]{3}{*}{ october 2014} & routine $\mathrm{CT}$ & 15 & $60 \%$ & 6 & $24 \%$ & 1 & $4 \%$ & 3 & $12 \%$ & 0 & $0 \%$ \\
\hline & emergency $\mathrm{CT}$ & 13 & $59 \%$ & 4 & $18 \%$ & 3 & $14 \%$ & 1 & $5 \%$ & 1 & $5 \%$ \\
\hline & both & 28 & $60 \%$ & 10 & $21 \%$ & 4 & $9 \%$ & 4 & $9 \%$ & 1 & $2 \%$ \\
\hline \multirow[t]{3}{*}{ november 2014} & routine $\mathrm{CT}$ & 9 & $50 \%$ & 3 & $17 \%$ & 2 & $11 \%$ & 3 & $17 \%$ & 1 & $6 \%$ \\
\hline & emergency CT & 14 & $61 \%$ & 4 & $17 \%$ & 3 & $13 \%$ & 2 & $9 \%$ & 0 & $0 \%$ \\
\hline & both & 23 & $56 \%$ & 7 & $17 \%$ & 5 & $12 \%$ & 5 & $12 \%$ & 1 & $2 \%$ \\
\hline \multirow[t]{3}{*}{ december 2014} & routine $\mathrm{CT}$ & 10 & $67 \%$ & 5 & $33 \%$ & 0 & $0 \%$ & 0 & $0 \%$ & 0 & $0 \%$ \\
\hline & emergency $\mathrm{CT}$ & 9 & $53 \%$ & 0 & $0 \%$ & 3 & $18 \%$ & 2 & $12 \%$ & 3 & $18 \%$ \\
\hline & both & 19 & $59 \%$ & 5 & $16 \%$ & 3 & $9 \%$ & 2 & $6 \%$ & 3 & $9 \%$ \\
\hline \multirow[t]{3}{*}{ january 2015} & routine $\mathrm{CT}$ & 3 & $43 \%$ & 3 & $43 \%$ & 0 & $0 \%$ & 1 & $14 \%$ & 0 & $0 \%$ \\
\hline & emergency $\mathrm{CT}$ & 10 & $45 \%$ & 5 & $23 \%$ & 4 & $18 \%$ & 2 & $9 \%$ & 1 & $5 \%$ \\
\hline & both & 13 & $45 \%$ & 8 & $28 \%$ & 4 & $14 \%$ & 3 & $10 \%$ & 1 & $3 \%$ \\
\hline \multirow[t]{3}{*}{ february 2015} & routine $\mathrm{CT}$ & 9 & $39 \%$ & 9 & $39 \%$ & 0 & $0 \%$ & 2 & $9 \%$ & 3 & $13 \%$ \\
\hline & emergency $\mathrm{CT}$ & 9 & $38 \%$ & 11 & $46 \%$ & 3 & $13 \%$ & 1 & $4 \%$ & 0 & $0 \%$ \\
\hline & both & 18 & $39 \%$ & 20 & $43 \%$ & 3 & $6 \%$ & 3 & $6 \%$ & 3 & $6 \%$ \\
\hline \multirow[t]{3}{*}{ total } & routine $\mathrm{CT}$ & 77 & $53 \%$ & 39 & $27 \%$ & 7 & $5 \%$ & 16 & $11 \%$ & 6 & $4 \%$ \\
\hline & emergency $\mathrm{CT}$ & 83 & $49 \%$ & 38 & $22 \%$ & 29 & $17 \%$ & 12 & $7 \%$ & 9 & $5 \%$ \\
\hline & both & 160 & $51 \%$ & 77 & $24 \%$ & 36 & $11 \%$ & 28 & $9 \%$ & 15 & $5 \%$ \\
\hline
\end{tabular}

abs = absolute value, BMI = body mass index; alert due to high body weight $\left(\geq 25 \mathrm{~kg} / \mathrm{m}^{2}\right)$, off-centering = patient was not positioned properly in isocenter, orth. hardware = orthopedic hardware; alert was caused by dose up-regulation due to orthopedic hardware, other = causes for alerts not covered by the aforementioned reasons; e. $\mathrm{g}$. dose up-regulation because of scan on spine-board, rel = relative value.

abs = absoluter Wert, BMI = Body-Mass-Index; die Dosiswarnung ist durch ein hohes Patientengewicht bedingt $\left(\geq 25 \mathrm{~kg} / \mathrm{m}^{2}\right)$, off-centering $=$ ungenaue Patientenlagerung im Isozenter des Scanners, orth. Hardware = die Dosiswarnung ist durch einliegendes Osteosynthesematerial und dadurch bedingter Dosis-Hochregulierung verursacht, other = die Dosiswarnung ist die Folge anderer Gründe wie beispielsweise durch Untersuchung auf einem Spineboard. rel= relativer Wert.

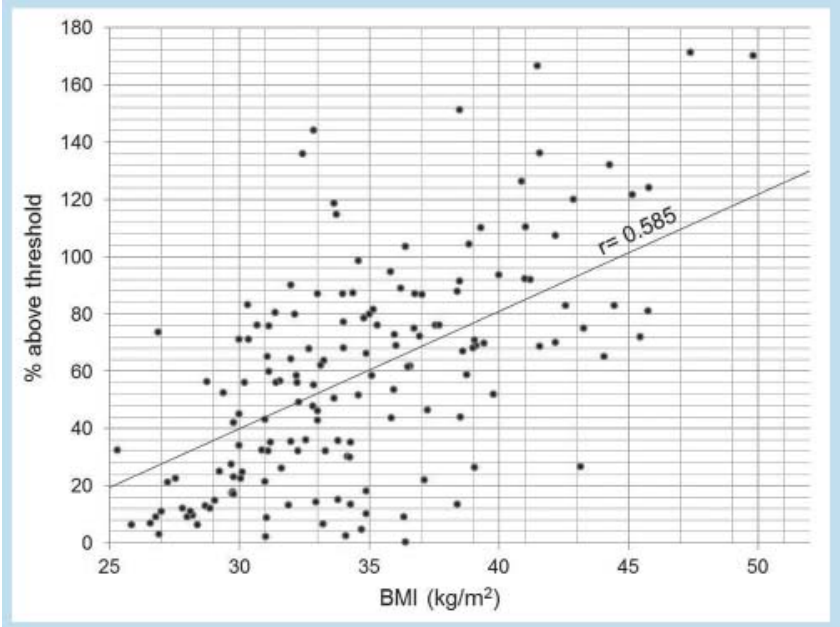

Fig. 3 Correlation of high body weight (BMI $\left.\geq 25 \mathrm{~kg} / \mathrm{m}^{2}\right)$ and dose above threshold (relative number). The Pearson coefficient $(r=0.585)$ shows a good correlation of both metrics.

Abb. 3 Die Höhe des Patientengewichts $\left(B M I \geq 25 \mathrm{~kg} / \mathrm{m}^{2}\right)$ korreliert gut mit dem relativen Dosiswert oberhalb des Schwellenwertes (Pearson-Korrelationskoeffizient $r=0,585$ ). and has led to the introduction of BMI-dependent tube voltage/ current selection at many sites $[9,28]$, which is now evaluated at our institution, too.

Furthermore, up-regulation of the tube current may be caused by orthopedic hardware within the scanning area, which was also more frequently detected on the clinical routine CT scanner. This is due to the fact that most patients with orthopedic hardware undergo scans on an outpatient basis. Irrespective of this, we now increasingly acquire orthopedic hardware examinations with the dual-energy technology due to fewer metal artifacts [29], which often involves dose reduction and a possible decline of alerts.

Our study has some limitations: (1) The training and experience of radiographers significantly influence the radiation exposure of patients $[3,14,21]$ and the quality of data depends on the accuracy of tagging, which might have skewed our results. However, a mean working experience of 8.32 years indicates that most radiographers involved in the study were well versed. (2) We used scanners from a single vendor, which may have affected dose values as, for example, tube current modulation techniques and bowtie filters vary among different vendors [25]. (3) In some patients alerts may have been caused by more than one source or an interaction of several causes (e.g. high BMI and off-centering). In these cases we tried to estimate which of the causes might have been the principal reason. However, we cannot exclude that our appraisal was 
inaccurate. (4) National DRLs have been introduced in many countries, but show considerable ranges $[11,13]$, so that our thresholds may not have been perfect, although they are lower than most published DRLs. (5) Finally, we based our analyses on CTDI ${ }_{v o l}$ and DLPs, although they have several disadvantages such as measurements done on phantoms that are much shorter than the average adult patient or inaccuracy when radiation dose-saving technologies are applied $[3,4,9]$. To account for these drawbacks, the sizespecific dose estimate (SSDE), which also considers patient anatomy, is used more and more [30] and should be included in further studies.

In summary, our study shows that dose monitoring software can be successfully implemented in clinical practice and provides important information on a patient's radiation dose. Besides being a tool for internal and external quality control, dose monitoring software can be used to improve awareness and knowledge of radiation doses. It will be the task of future research to assess longer-term effects of dose monitoring software in terms of dose reduction and decrease of alerts caused by human error as well as to evaluate the impact of adaptation of scanning parameters to patient-specific factors.

Clinical relevance

- Increasing radiation exposure of patients due to medical imaging has made the registration and control of radiation dose more and more a topic of interest.

- Dose monitoring software is an important tool to collect and analyze radiation dose data and allows for internal and external quality control.

- By revealing sources of a radiation dose above predefined thresholds, dose monitoring software not only increases radiation awareness but may also lead to an improvement in radiation protection.

\section{References}

1 Amis ES, Butler PF, Applegate KE et al. American College of Radiology white paper on radiation dose in medicine. J Am Coll Radiol JACR 2007; 4: $272-284$

2 Schauer DA, Linton OW. National Council on Radiation Protection and Measurements report shows substantial medical exposure increase. Radiology 2009; 253: 293-296

3 Boone JM, Hendee WR, McNitt-Gray MF et al. Radiation exposure from CT scans: how to close our knowledge gaps, monitor and safeguard exposure-proceedings and recommendations of the Radiation Dose Summit, sponsored by NIBIB, February 24-25, 2011. Radiology 2012; 265: $544-554$

4 Robinson TJ, Robinson JD, Kanal KM. Implementation of the ACR dose index registry at a large academic institution: early experience. J Digit Imaging 2013; 26: 309-315

5 Brink JA, Amis ES. Image Wisely: a campaign to increase awareness about adult radiation protection. Radiology 2010; 257: 601 -602

6 Goske MJ. Image gently: child-sizing radiation dose for children. JAMA Pediatr 2013; 167: 1083
7 Strauss KJ, Goske MJ, Kaste SC et al. Image gently: Ten steps you can take to optimize image quality and lower CT dose for pediatric patients. Am J Roentgenol Am J Roentgenol 2010; 194: 868-873

8 European Society of Radiology (ESR). Renewal of radiological equipment. Insights Imaging 2014; 5: 543-546

9 McCollough CH, Leng S, Yu L et al. CT dose index and patient dose: they are not the same thing. Radiology 2011; 259: 311 - 316

10 Neumann RD, Bluemke DA. Tracking radiation exposure from diagnostic imaging devices at the NIH. J Am Coll Radiol. JACR 2010; 7: 87-89

11 Treier R, Aroua A, Verdun FR et al. Patient doses in CT examinations in Switzerland: implementation of national diagnostic reference levels. Radiat Prot Dosimetry 2010; 142: 244-254

12 Brenner DJ, Hall EJ. Cancer risks from CT scans: now we have data, what next? Radiology 2012; 265: 330-331

13 Hendee WR, O'Connor MK. Radiation risks of medical imaging: separating fact from fantasy. Radiology 2012; 264: 312 - 321

14 Sadigh G, Khan R, Kassin MT et al. Radiation safety knowledge and perceptions among residents: a potential improvement opportunity for graduate medical education in the United States. Acad Radiol 2014; 21: 869-878

15 Verdun FR, Gutierrez D, Vader JP et al. CT radiation dose in children: a survey to establish age-based diagnostic reference levels in Switzerland. Eur Radiol 2008; 18: 1980-1986

16 Einstein AJ. Effects of radiation exposure from cardiac imaging: how good are the data? J Am Coll Cardiol 2012; 59: 553-565

17 Armao D, Smith JK. The health risks of ionizing radiation from computed tomography. N C Med J 2014; 75: 126-128-131

18 Hall EJ, Brenner DJ. Cancer risks from diagnostic radiology: the impact of new epidemiological data. Br J Radiol 2012; 85: e1316-e1317

19 Brenner DJ, Shuryak I, Einstein AJ. Impact of reduced patient life expectancy on potential cancer risks from radiologic imaging. Radiology 2011; 261: $193-198$

20 Brenner DJ, Hall EJ. Computed tomography-an increasing source of radiation exposure. N Engl J Med 2007; 357: 2277-2284

21 AlSuwaidi JS, AlBalooshi LG, AlAwadhi HM et al. Continuous monitoring of CT dose indexes at Dubai Hospital. Am J Roentgenol Am J Roentgenol 2013; 201: $858-864$

22 Rehani $M$, Frush D. Tracking radiation exposure of patients. Lancet 2010; 376: $754-755$

23 Chintapalli KN, Montgomery RS, Hatab M et al. Radiation dose management: part 1, minimizing radiation dose in CT-guided procedures. Am J Roentgenol Am J Roentgenol 2012; 198: W347-W351

24 Kaasalainen T, Palmu K, Lampinen A et al. Effect of vertical positioning on organ dose, image noise and contrast in pediatric chest CT-phantom study. Pediatr Radiol 2013; 43: 673-684

25 Kaasalainen T, Palmu K, Reijonen $V$ et al. Effect of patient centering on patient dose and image noise in chest CT. Am J Roentgenol Am J Roentgenol 2014; 203: 123-130

26 Habibzadeh MA, Ay MR, Asl ARK et al. Impact of miscentering on patient dose and image noise in $\mathrm{x}$-ray $\mathrm{CT}$ imaging: phantom and clinical studies. Phys Medica PM Int J Devoted Appl Phys Med Biol Off J Ital Assoc Biomed Phys AIFB 2012; 28: 191 - 199

27 Raman SP, Mahesh M, Blasko RV et al. CT Scan Parameters and Radiation Dose: Practical Advice for Radiologists. J Am Coll Radiol 2013; 10: $840-846$

28 Wang G, Gao J, Zhao $S$ et al. Achieving consistent image quality and overall radiation dose reduction for coronary CT angiography with body mass index-dependent tube voltage and tube current selection. Clin Radiol 2014; 69: 945 -951

29 Winklhofer S, Benninger E, Spross C et al. CT metal artefact reduction for internal fixation of the proximal humerus: value of mono-energetic extrapolation from dual-energy and iterative reconstructions. Clin Radiol 2014; 69: e199-e206

30 Turner AC, Zhang $D$, Khatonabadi $M$ et al. The feasibility of patient sizecorrected, scanner-independent organ dose estimates for abdominal CT exams. Med Phys 2011; 38: 820-829 